\title{
A Study on the Effects of Teachers' Classroom Nonverbal Behaviors on Freshmen's Foreign Language Anxiety
}

\author{
HUA Min \\ School of Foreign Languages, \\ Wuhan Textile University \\ Wuhan, China \\ E-mail: Rebecca_huamin@126.com
}

\begin{abstract}
Abstrac $t$ - The research employed both quantitative and qualitative methods. 50 freshmen from Wuhan Textile University participate in the study. The whole procedure lasted for 8 weeks. At the beginning of the research, i.e. the first week, the questionnaires for evaluation of teacher's classroom nonverbal behavior and students' English learning anxiety were distributed to all participants in class. After the data in the questionnaire of evaluation were collected, the teacher modified her classroom nonverbal behaviors referring to the results.
\end{abstract}

Keywords-Classroom nonverbal behavior; Freshmen; Behavior modification; Foreign language anxiety (FLA)

\section{INTRODUCTION}

Foreign language anxiety is a key affective factor in language learning, it is associated with negative feelings such as uneasiness, frustration, self-doubt, apprehension and tension. The foreign language anxiety here is described as the fear or the apprehension occurring when a learner is expected to perform in the second or foreign language. In the early 80's of 20th century, researchers began to understand the latent relationship between anxiety and foreign language learning performance but they failed to get a definite answer. At present, there are numerous researches on nonverbal behaviors both abroad and in China. But very few related researches were carried out to study the effects of teacher's classroom nonverbal behaviors on student's foreign language anxiety. Most previous studies on foreign language anxiety focus on the field of learner's affective factors to find out ways in reducing it, such as from the perspective of its relationship with attitudes, motivation, and self-esteem. Very few related researches connected it to teacher's classroom nonverbal behaviors. The present study attempts to explore the relationship between teacher's classroom nonverbal behaviors and students' foreign language anxiety, whether or not nonverbal behavior can affect students' FLA (Foreign Language Anxiety). The researchers' studies also show the negative correlation of anxiety with grades in language courses, proficiency test performance, performance in writing and speaking tasks, self-confidence in language learning and self-esteem, etc.

\section{METHODOLOGY}

\section{A. Research Questions}

The study aims to look into the effects on the foreign language anxiety of non-English major college students through the analysis of teachers' classroom nonverbal behaviors (Proxemics, Kinesics, Chronemics, Physical attractiveness and artifact of teachers, Paralanguage). It has utilized two main methodologies: quantitative study and qualitative study. Questionnaire and interview were designed to obtain data. This thesis attempts a study to answer two important questions through investigation. RQ 1 What is the general situation of teachers' nonverbal behaviors in College English classroom? And how are the students satisfied with them? RQ 2 What is the relationship between teacher's classroom nonverbal behaviors and students' foreign language anxiety?

\section{B. Subjects}

The subjects in this study are seventy non-English major students who upgraded from freshmen in Wuhan Textile University (WTU) in the year of 2014. The investigation was carried out in the first semester of their first year as university students, twenty-four majored in International Trade and another twenty-six subjects majored in the Computer Science. Of the fifty students, aged from 17 to 19 , 21 are male, and 29 are female, all of whom had formally studied English as their foreign language for 6 years in junior and senior high schools. Student subjects were chosen randomly.

\section{Instruments}

Three instruments were used to gather the data for this study: 1) two questionnaires 2) an interview 3) SPSS 13.0 software

\section{The Questionnaires}

There are two questionnaires for the research, one for students' evaluation of teacher's classroom nonverbal behavior, the other for levels of students' foreign language anxiety (FLCAS) in English learning. In order to identify students' attitudes towards the teacher in classroom, a questionnaire was constructed with the reference to questionnaires in Zhou Pengsheng (2003) "The Quantifying Study on Teachers' Nonverbal Behavior in Classroom Instruction" to the students to examine their degrees of satisfaction about the teacher. The questionnaire includes 20 items, which would cover all the aspects of teacher's classroom nonverbal behaviors the author wants to study in this thesis. Item one to four were designed for the 
evaluation of teacher's proxemics in classroom; item five to nine for kinesics; item ten to thirteen for chronemics; item fourteen to sixteen for physical attractiveness and artifact of teacher; item seventeen to twenty for

\section{E. Data Collection and Analysis}

A total of 50 questionnaires distributed were all collected. Sets of scores of the questionnaire were collected, namely: the scores of the evaluation of teacher's classroom nonverbal behaviors. The participants' test scores and data collected through the questionnaire were input into SPSS 13.0 for analyses.

\section{FINDINGS AND DISCUSSION}

\section{A. Results from the Questionnaires}

Results of the questionnaire on students' evaluation of teacher's classroom nonverbal behaviors

In this questionnaire, the total 20 items could be divided into five parts which respectively concerns an aspect of teacher's classroom nonverbal behaviors that would be studied in the thesis, namely: Part 1---Item one to four, designed for the evaluation of teacher's proxemics in classroom, Part 2---item five to nine, for kinesics, Part 3---item ten to thirteen, for chronemics, Part 4---item fourteen to sixteen, for physical attractiveness and artifact of teacher, Part 5---item seventeen to twenty, for teacher's paralanguage. Each item provides a positive description of an aspect of teacher's classroom nonverbal behavior. For each item, the evaluation scale was assigned a scale of 1,2 , 3, 4, 5 points, ranging from "strongly agree" to "strongly disagree". Then total scores for each part were summed to create an overall evaluation score according to the following formula: Overall evaluation score=Total scores $\div$ Student number $\div$ Item number That is to say, the lower the overall evaluation score is, the higher the degree of teacher's evaluation will be. The evaluations for each part were graphed below. Then the results for each of them were discussed separately.

Figure 3.1 Overall evaluation score

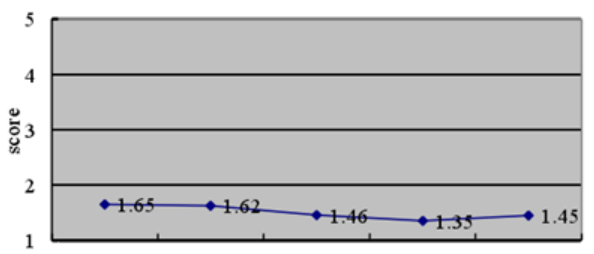

Note: Part $1=$ Pro $\quad$ Part $2=$ Kin $\quad$ Part $3=$ Chr $\quad$ Part $4=$ Phy Part $5=$ Par

Note: Part 1=Pro; Part 2=Kin; Part 3=Chr; Part 4= Phy; physical attractiveness and artifact of teacher; Part 5=Par

Figure 3.1 clearly shows the students' overall degrees of satisfaction on teacher's classroom nonverbal behaviors. They are most satisfactory with teacher's physical attractiveness and artifact and least satisfactory with teacher's proxemics. But generally speaking, most students had positive evaluations towards teacher's nonverbal behaviors because the overall evaluation scores for the five parts were all below 2, which mean the average students' attitudes were between "strongly agree" and "agree". Moreover, the figure points out the problems in teacher's classroom nonverbal behaviors and will be explained in detail with reference to the following charts.

For each part, the average evaluation score of every item can be used to find out students' attitudes towards specific aspects of nonverbal behaviors in this category. The formula is as follows:

Average evaluation score $=$ Total scores $\div$ Student number

Figure 3.2 Average evaluation score for Part 1(Proxemics)

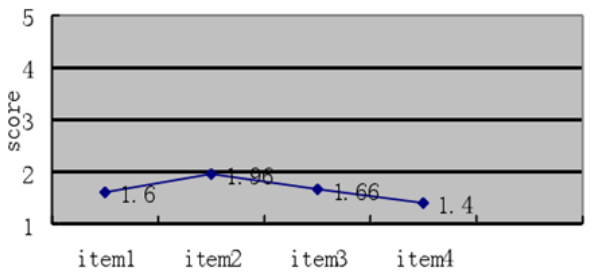

The four items in part 1 are concerning about teacher's proxemics, which refers to where teacher places herself to do certain tasks, the use of specific locations for conveying specific types of information. From the above analysis, we can see that this is the part that students were least satisfactory with. So, much emphasis should be laid on the modification of teacher's proxemics. Among the four items, item 2 (teacher's walk around the classroom) gains the least satisfaction. That's probably because the research setting is the English listening class, in which the teacher had to sit in the front to play the tape of the textbook and control the rhythm of the whole class. Likewise, students were also unsatisfactory with item 3 (proper teacher-student distance) and item 1 (staying in the platform) Item 4 (proper distance when doing classroom activities) is the most satisfactory one from students. All the above mentioned reminds the teacher that she should pay much attention to her distance with the students and location in the classroom.

Figure 3.3 Average evaluation score for Part 2(Kinesics)

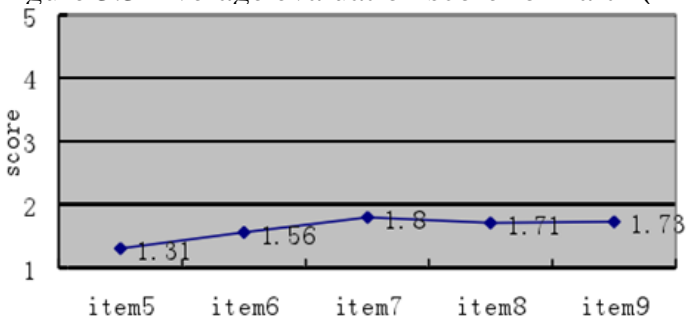

In part 2, the five items are descriptions about teacher's kinesics, which means teachers' body movement, posture, and facial and eye behavior, etc. This is the part that students were second least satisfactory with. Among the five items, students were most satisfactory with item 5 (appropriate talking, behaviors and rich facial expressions) and second most satisfactory with item 6 (natural gestures and postures) Item 8 (encouraging eye contact, gestures etc.) is in the middle. For the two least satisfactory ones, item 7 (frequent eye contact) and 9 (rich facial expressions and eye contact to stop misbehaviors) Figure 3.3 just indicates the 
importance of teacher's eye contact in the classroom.

Figure 3.4 Average evaluation score for Part 3(Chronemics)

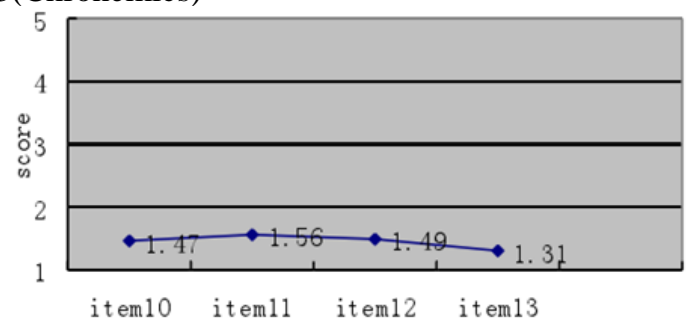

Part 3 is about teacher's chronemics, i.e. the teachers' concept of time and use of time. It deals with how the teacher uses time to do certain tasks, the use of specific time for providing specific types of information, to create a certain environment to work or to relax. The four average scores in this part are closer than in other parts, which indicate students' evaluations of the four aspects are relatively alike. From item 13 (patient help for students), item 10 (concentration when students are answering questions) to item 12 (reasonable schedule of class) and item 11 (good control of class time), the degrees of satisfaction are from higher to lower. So, the teacher should further improve her control of class time.

Figure 3.5 Average evaluation score for Part 4 (Physical attractiveness and artifact of teacher)

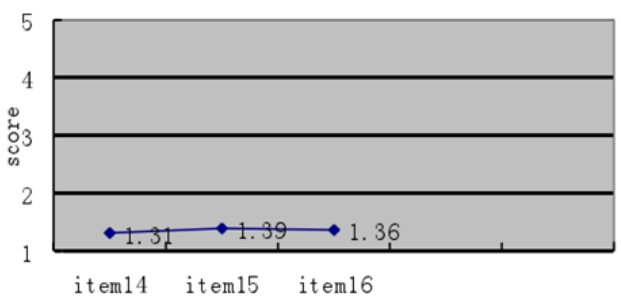

Part 4 is the part that students were most satisfactory with, with the overall evaluation score of 1.35 . It refers to the physical attractiveness and artifact of the teacher. The data shows that most students feel good about teacher's clothing and other physical attractiveness i.e. item 14 (teacher's plain and natural clothing), item 16 (appropriate artifact) and item 15 (appropriate hairstyle and clothing).

Figure 3.6 Average evaluation score for Part 5 (Paralanguage)

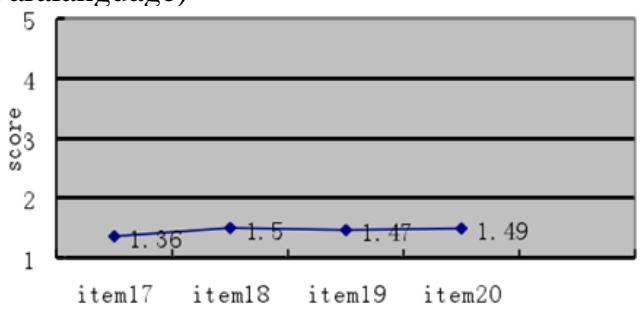

Part 5 is of the second most satisfaction among the five parts of teacher's evaluation which is concerning about the paralanguage. It deals with how something is said and not what is said i.e. the range of nonverbal vocal cues surrounding common speech behavior, including teachers' tone, volume, stress and stop of words. There are four items in this part, item17 (teacher's appropriate tone, volume etc), item 19 (teacher's proper speed of talking), item 20 (proper use of the stop of words) and item 18 (good command of cadence). The four items are in turn from higher satisfaction to lower satisfaction. In general, most students are fairly satisfactory with this part and the teacher can make some modifications accordingly.

Results of the FLCAS (Foreign Language Classroom Scale)

Figure 3.7 Paired Samples Statistics

\begin{tabular}{|c|c|c|c|c|c|}
\hline & & Mean & $\mathrm{N}$ & Std Deviation & $\begin{array}{l}\text { Std. Error } \\
\text { Mean }\end{array}$ \\
\hline \multirow[t]{2}{*}{ Pair 1} & PRETOTAL & 96.7571 & 70 & 21.48369 & 256779 \\
\hline & $\begin{array}{l}\text { POSTTOTA } \\
\text { L }\end{array}$ & 101.9143 & 70 & 18.60944 & 222425 \\
\hline \multirow[t]{2}{*}{ Pair 2} & PRET & 8.2714 & 70 & 240122 & .28700 \\
\hline & POSTT & 8.3714 & 70 & 2.41476 & .28862 \\
\hline \multirow[t]{2}{*}{ Pair 3} & PREF & 10.1857 & 70 & 268810 & 32129 \\
\hline & POSTF & 10.8571 & 70 & 222167 & 26554 \\
\hline \multirow[t]{2}{*}{ Pair 4} & PREC & 36.3714 & 70 & 10.49799 & 1.25475 \\
\hline & POSTC & 39.6286 & 70 & 8.55362 & 1.02235 \\
\hline \multirow[t]{2}{*}{ Pair 5} & PREA & 26.8714 & 70 & 5. 29403 & 63276 \\
\hline & POSTA & 27.2857 & 70 & 5.13059 & 61322 \\
\hline \multirow[t]{2}{*}{ Pair 6} & PREN & 15.0571 & 70 & 3. 85568 & 46084 \\
\hline & POSTN & 15.7714 & 70 & 4.02230 & 48076 \\
\hline
\end{tabular}

Note: PRETOTAL and POSTTOTAL means the pretest total score and posttest total score of the FLCAS respectively

PREF \& POSTF, PREC \& POSTC, PREA \& POSTA and PREN \& POSTN refer to the pretest and posttest total score of each sub-scale respectively

Figure 3.9 Paired Samples Test

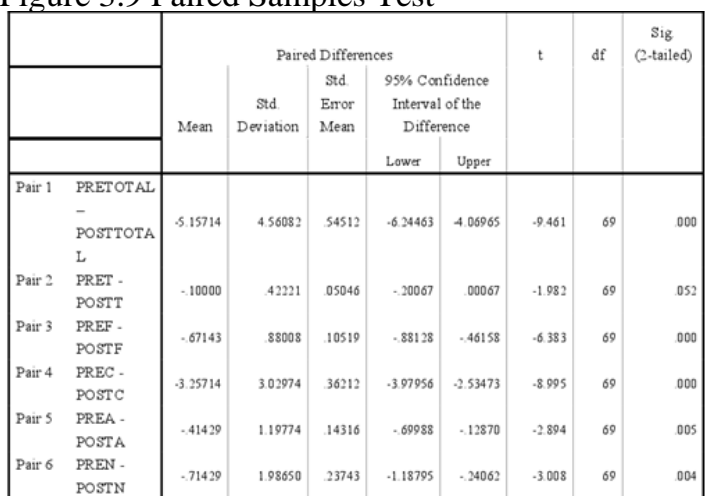

In this section, the paired sample t-test was conducted to compare the difference before and after teacher's modification. In the table of paired samples of statistics, the mean score was 96.7571 for PRETOTAL and 101.9143 for POSTTOTAL (see Figure 3.7). A review of the mean scores of the five sub-scales also indicated that all the posttest mean scores were more or less higher than the ones of the pretest. However, the significance for each item analyzed were $0.000,0.052,0.000,0.000,0.005,0.004$ (see Figure 3.9) which indicates the insignificant difference between the subscale PRET and POSTT as well as the significant difference between PRETOTAL and 
POSTTOTAL and the other four sub-scales tested. But as it can be seen from Figure 3.9, the Lower and Upper 95\% Confidence Interval of the Difference is -.20067 and .00067 which contains .00000, it means there is no significant difference between the two variables PRET and POSTT. Meanwhile, the Sig. of the 2-tailed t-test for the pair PRET and POSTT is .052 $(>0.05)$

which shows the difference between PRET and POSTT is insignificant. Therefore, we can come to the conclusion that teacher's classroom nonverbal behaviors had no significant effect on students' English test anxiety. The results also revealed that the overall foreign language anxiety of the students has been lessened.

\section{B.Major Findings and Discussion}

It is clear from this study that in the situation of intercultural communication, teachers' nonverbal behaviors could affect students' foreign language anxiety. If a teacher makes an effort to improve his/her nonverbal behavior, undoubtedly, it will promote English teaching and learning in the classroom. Based on the results presented in the questionnaire and the interview, some major findings are that A high level of satisfaction on teacher's overall nonverbal behaviors in English classroom; Students' greatest satisfaction towards teacher's physical attractiveness and artifact; Students' similar degrees of satisfaction for teacher's paralanguage and chronemics; Students' relatively lower levels of satisfaction for teacher's proxemics and kinesics in classroom.

\section{IV.CONCLUSION}

The study finds out the general situation of teachers' nonverbal behaviors in college English classroom. These nonverbal codes have a considerable effect on students' foreign language anxiety. Teachers who use these codes positively and actively find it less difficult to achieve effective teaching and lessen students' foreign language anxiety, while others who are not so active in using positive nonverbal codes have more difficulty communicating with students, performing poorly in the classroom, thus have little impact on the lessening of students' English learning anxiety. The result of this study is confirmed by the teacher evaluation questionnaire, FLCAS and the interview. The study deals with the most frequently employed nonverbal communication behaviors of five categories: Kinesics, proxemics, chronemics, paralanguage and physical attractiveness and artifact of teachers. The effective nonverbal behavior in the classroom, which was specifically discussed, on teachers' part, is very crucial to lessen students' foreign language anxiety. It is found that teachers need to be aware of their nonverbal behaviors in the classroom, for it is helpful for teachers to acquire the ability to send accurate messages and to become more proficient at receiving students' messages. It is important that teachers understand the role nonverbal behavior plays during the course of a day in a classroom.

\section{REFERENCE}

[1]Knapp, M., \& Hall, J. Nonverbal Communication in Human Interaction. (3rd ed.). [M]New York: Forth Worth, TX: Harcourt Brace. 1992
[2]MacIntyre, P. D. and Gardner, R.C. The Subtle Effects of Language Anxiety on Cognitive [3] Processing in the Second Language [J]. Language Learning, 1994, (44), 283-305.

[3]Woolfolk, A., \& Brooks, D. (1983). Nonverbal Communication in Teaching and Cultural Implications. New York: Academic Press

[4] Sarason, LG. (1984). Stress, anxiety, and cognitive interference: Reactions to tests. Journal of Personality and Social Psychology, 46, 929-938. 